\title{
The Effect of Chloramphenicol on Growth and Mitochondrial Function of the Flagellate Polytomella caeca
}

\author{
By D. LLOYD, D. A. EVANS AND SUSAN E. VENABLES \\ Medical Research Council Group for Microbial Structure and Function, Department \\ of Microbiology, University College, Cathays Park, Cardiff, CFI $3 N R$
}

(Accepted for publication 8 December 1969)

\begin{abstract}
SUMMARY
Chloramphenicol (I $\mathrm{mg} . / \mathrm{ml}$.) increased the mean doubling time of Polytomella caeca from 3.6 to $5 \mathrm{hr}$ and gave $62 \%$ inhibition of the final yield of organisms on an acetate + mineral salts + thiamine medium. The rates of acetate oxidation and tetrazolium reduction by whole organisms decreased progressively when grown in the presence of increasing chloramphenicol concentrations; no ultrastructural abnormalities of the mitochondria of such organisms were seen in electron micrographs. Succinoxidase and NADH oxidase activities of isolated mitochondria were decreased by $43 \%$ and $72 \%$, respectively, by growth of organisms with $\mathrm{r}$ mg. chloramphenicol/ml. The content of cytochromes $\left(a+a_{3}\right)$ was decreased by $40 \%$, and cytochrome oxidase activity was about $50 \%$ that of normal mitochondria. No alteration in the activities of rotenone-sensitive NADHcytochrome $c$ oxidoreductase or succinate-cytochrome $c$ oxidoreductase was detected, using mammalian cytochrome $c$ as electron acceptor. However, the rate of reduction of electron-transport components during the aerobicanaerobic transition (with succinate as substrate) suggested that the supply of electrons to the respiratory chain was rate-limiting and might be more important in leading to respiratory deficiency than the decreased cytochrome oxidase activity. No major cytochrome dislocation was detected, suggesting that the respiratory chain was itself intact.
\end{abstract}

\section{INTRODUCTION}

Chloramphenicol is an inhibitor of growth of several eucaryotic micro-organisms. High concentrations are necessary to inhibit the growth of Tetrahymena pyriformis (Mager, I960; Turner \& Lloyd, I970) and various species of yeast (Clark-Walker \& Linnane, 1967), while some strains of Saccharomyces cerevisiae are sensitive to lower concentrations of the drug (Wilkie, Saunders \& Linnane, 1967). The effect of chloramphenicol in eucaryotes appears to be specific inhibition of mitochondrial protein synthesis: certainly, in vitro sensitivity of mitochondrial systems from many sources has been demonstrated (Mager, I960; Kroon, I963; Lamb, Clark-Walker \& Linnane, I968).

Mitochondria of yeast cells grown with chloramphenicol have altered morphology, the cristae are less well defined than in normal cells; they also have a lower content of membrane-bound cytochromes (Huang, Biggs, Clark-Walker \& Linnane, 1966). Indirect evidence suggests that the primary effect of chloramphenicol as a specific inhibitor of protein synthesis on mitochondrial ribosomes is unlikely to be on cytochrome synthesis itself. The only product of in vitro mitochondrial synthesis as yet 
identified is a hydrophobic ('structural') protein (Roodyn, I962; Haldar, Freeman \& Work, 1966). Woodward \& Munkres (I966) showed that alterations in the primary structure of such a protein resulting from an extrachromosomal mutation in Neurospora can lead to a pleiotropic respiratory deficiency due to altered binding of respiratory chain components. Thus chloramphenicol may act on the synthesis of 'structural' components necessary for the organization of the specific membrane configuration essential for integrated mitochondrial respiratory function.

The present work shows that chloramphenicol at high concentrations also inhibits the growth of the obligately aerobic flagellate Polytomella caeca. Although no change in mitochondrial ultrastructure can be seen in the electron microscope, the efficiency of mitochondrial electron transport is markedly decreased and impairment of the mechanism can be located biochemically at the flavoprotein region of the respiratory chain.

\section{METHODS}

Maintenance, growth and harvesting of the organism. Polytomella caeca Pringsheim was obtained in pure culture from the Culture Collection of Algae, Department of Botany, Indiana University, Bloomington, Ind., U.S.A. Growth and harvesting procedures have been described previously (Lloyd \& Chance, I968; Lloyd, Evans \& Venables, 1968). Chloramphenicol was added as a solid to culture flasks after sterilization of the medium by autoclaving at $\mathrm{I} 2 \mathrm{I}^{\circ}$ for $20 \mathrm{~min}$.

Preparation of cell-free extracts and isolation of mitochondria. The preparation of mitochondrial suspensions was as described previously (Lloyd \& Chance, I968; Lloyd, Evans \& Venables, I968).

Analytical methods. Measurements of oxygen uptake by whole cell suspensions were made in a conventional Warburg apparatus (Umbreit, Burris \& Stauffer, 1957). Polarographic measurements of oxygen uptake by mitochondrial suspensions were made with an oxygen electrode (Lloyd \& Brookman, 1967). The reduction of 2,3,5-triphenyl tetrazolium chloride was followed by extraction of the red formazan in acetone and measurement of the extinction of the resulting solutions at $55^{\circ} \mathrm{nm}$. $\left(\epsilon=445^{\circ}\right)$. Measurements of the total cytochrome and flavoprotein content of mitochondria were performed by using a Cary model 14 split-beam spectrophotometer fitted with a 0 to $0 \cdot I$ extinction slide wire. Values were calculated from difference spectra (dithionite-reduced, oxidized), using the published extinction coefficients for the mammalian electron-transport components. Values for flavoproteins may include a contribution from non-haem iron, which also has an absorption at $465 \mathrm{~nm}$. Steady-state reduction levels and half-times for reduction of components during the aerobic-anaerobic transition (state $4 \rightarrow$ state 5 , Chance \& Williams, 1956) were measured with a dualwavelength spectrophotometer (Chance, 1951). These measurements and those of oxygen uptake by mitochondrial suspensions were made in a buffer consisting of 0.25 M-sucrose +2 mM-EGTA (ethyleneglycol-bis $\left(\beta\right.$-amino-ethyl ether) $N, N^{1}$-tetraacetic acid) $+\mathrm{I} 5 \mathrm{~mm}-\mathrm{KH}_{2} \mathrm{PO}_{4}+$ bovine serum albumin $0.15 \%(\mathrm{w} / \mathrm{v})$ at $\mathrm{pH} 7.4$. Protein was measured by the method of Lowry, Rosebrough, Farr \& Randall (I95I).

Enzyme assays. NADH-cytochrome $c$ reductase $\left(\mathrm{NADH}_{2}:\right.$ cytochrome $c$ oxidoreductase EC I.6.2.I) was assayed in the presence of rotenone (20 m $\mu$ moles/ $\mathrm{mg}$. protein) in the mitochondrial isolation buffer $(0.32 \mathrm{M}$-sucrose $+2 \mathrm{mM}-\mathrm{EGTA}+20$ mM-tris $\mathrm{HCl}, \mathrm{pH} 7 \cdot 4$ ). Succinate-cytochrome $c$ oxidoreductase was measured as 
previously described. Both these assays were made at various cytochrome $c$ concentrations, and a value for rates at infinite concentration of electron acceptor was obtained from a Lineweaver-Burk plot (Lloyd, I966). Cytochrome $c$ oxidase (cytochrome $c$ : oxidoreductase EC I.9.3.I) was measured by the method of Smith (1955), using mammalian cytochrome $c$ which had been reduced by exposure to hydrogen and palladized asbestos.

Electron microscopy. Organisms were fixed in phosphate-buffered $\mathrm{I} \cdot 5 \%$ glutaraldehyde at $\mathrm{pH} 7.4$ for 15 min., rinsed thoroughly in the phosphate buffer before postfixation in $\mathrm{I} \%$ osmium tetroxide in phosphate buffer $(\mathrm{pH} 7 \cdot 4)$ for $\mathrm{I} \mathrm{hr}$ and steeped in $0.5 \%(\mathrm{w} / \mathrm{v})$ uranyl acetate for $\mathrm{I} 2 \mathrm{hr}$. After dehydration in ethanol, embedding was in Araldite. Sections were cut at a nominal $500 \AA$ thickness (grey/silver colour) with an LKB Ultramicrotome, and stained on the grids with lead citrate. Negativestaining was with $\mathrm{K}$ phosphotungstate ( $\mathrm{pH} \mathrm{6.8)} \mathrm{(Parsons,} \mathrm{1963).} \mathrm{The} \mathrm{specimens} \mathrm{were}$ examined and photographed in an AEI EM6 at $60 \mathrm{kV}$.

Materials. Chloramphenicol was obtained both from Boots Pure Drug Co. Ltd., Nottingham, and from Parke-Davis \& Co., Hounslow, Middlesex. $\left[{ }^{14} \mathrm{C}\right]$ chloramphenicol was from the Radiochemical Centre, Amersham, Bucks. NADH and cytochrome $c$ were from Sigma Chemical Co., St Louis.

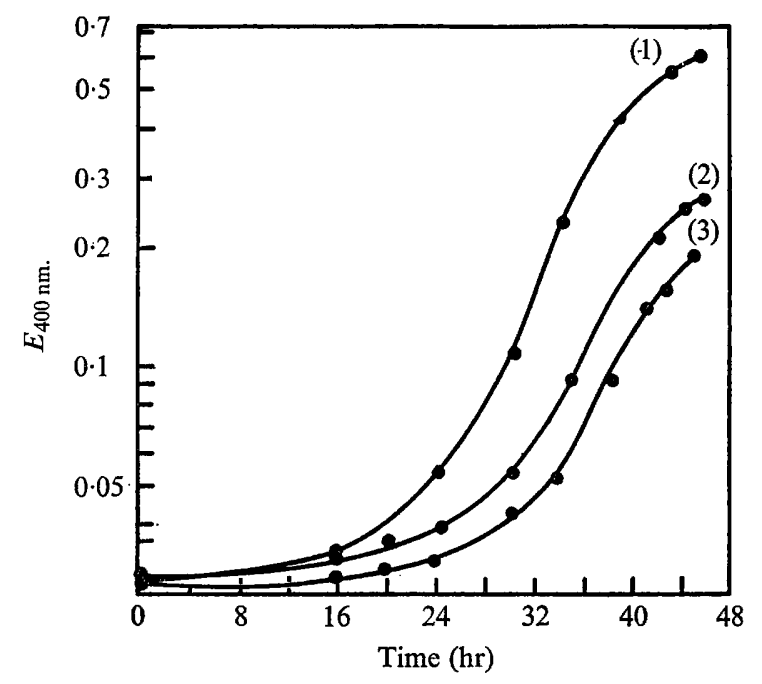

Fig. I. Growth of Polytomella caeca with acetate in the presence of chloramphenicol. Cultures were grown at $25^{\circ}$ with gentle forced aeration from standard small inocula (0.05 mg. dry wt) of acetate-grown organisms. (I) No chloramphenicol present; (2) + chloramphenicol $0.5 \mathrm{mg} . / \mathrm{ml}$; (3) + chloramphenicol I mg. $/ \mathrm{ml}$.

\section{RESULTS}

\section{Experiments with whole organisms}

Growth in the presence of chloramphenicol. In the absence of chloramphenicol the growth rate reached a maximum after about $30 \mathrm{hr}$; at this stage the organisms were growing exponentially with a mean doubling time of $3.6 \mathrm{hr}$ (Fig. I). In the presence of chloramphenicol (I mg. $/ \mathrm{ml}$.) the mean doubling time was $5.6 \mathrm{hr}$ after a similar lag period. A progressive decrease in yield of organisms (at $42 \mathrm{hr}$ ) with increasing 
chloramphenicol concentration was also observed; I $\mathrm{mg}$. chloramphenicol $/ \mathrm{ml}$. led to a $62 \%$ decrease.

Oxidative capacity. Organisms grown with chloramphenicol showed a decreased capacity for the oxidation of acetate (Fig. 2). Organisms taken from a culture containing chloramphenicol I mg./ml., when washed and incubated with acetate as a non-proliferating organism suspension, oxidized this substrate at two-thirds of the normal rate. There was a similar decrease in the ability of whole organisms to reduce 2,3,5-triphenyl tetrazolium chloride (Fig. 2).

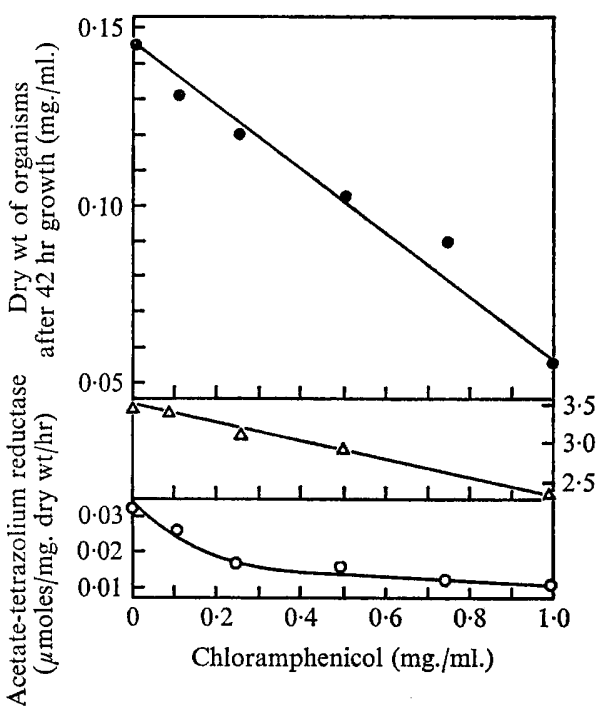

Fig. 2

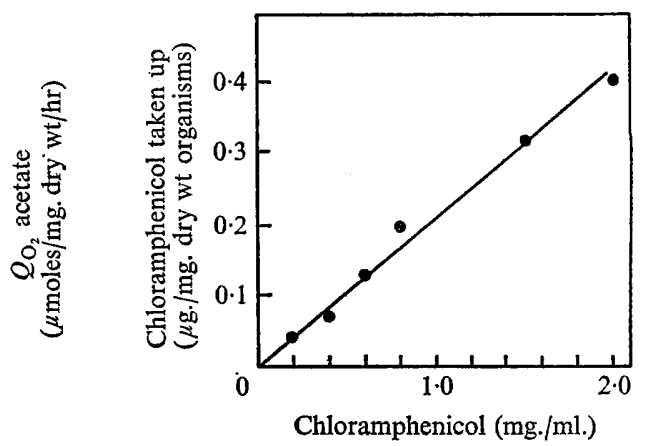

Fig. 3

Fig. 2. Yields of Polytomella caeca after $42 \mathrm{hr}$ growth in acetate medium at various chloramphenicol concentrations, and the rates of acetate oxidation and tetrazolium reduction by such cells. Shake cultures (Io $\mathrm{ml}$.) were grown from small standard (equiv. $0.02 \mathrm{mg}$. dry wt organism) inocula. Growth was measured by measuring extinctions of suspensions at $400 \mathrm{~nm}$. and converting to dry wt by means of a calibration curve (e). The $Q_{\mathrm{O}_{2}}$ values for acetate oxidation $(\triangle)$ were measured manometrically. The acetate $+2,3,5-$ triphenyl tetrazolium reductase activities $(O)$ were assayed by following the extinction at $550 \mathrm{~nm}$. of acetone extracts of the red formazan produced as a result of the reduction of the tetrazolium salt.

Fig. 3. Uptake of chloramphenicol by acetate-grown Polytomella caeca. Flasks containing $5.2 \mathrm{mg}$. dry wt organisms in acetate medium were incubated for $\mathrm{I} \mathrm{hr}$ in the presence of various concentrations of (methylene- ${ }^{14} \mathrm{C}$ )-D-threo-chloramphenicol. Samples of whole organisms were washed 4 times with growth medium and then assayed for radioactivity in an I.D.L. 'Tritomat' liquid scintillation counter, using the scintillation mixture described by Bray (1960).

Uptake of chloramphenicol. Organisms incubated in growth medium took up (methylene- ${ }^{14} \mathrm{C}$ )-D-threo-chloramphenicol; retention of the label was proportional to the concentration of the antibiotic in the medium (Fig. 3). The packed volume of Polytomella caeca has been measured as $13.9 \mu \mathrm{l} . / \mathrm{mg}$. dry wt and of this volume $50 \%$ is extracellular water. The figure of $0.4 \mu \mathrm{g}$. chloramphenicol $/ \mathrm{mg}$. dry wt of organisms, retained at a chloramphenicol concentration of $0.2 \mathrm{mg} . / \mathrm{ml}$. medium, 
corresponds to a maximum intracellular concentration of about $70 \mu \mathrm{g}$. chloramphenicol $/ \mathrm{ml}$. This result suggests that the organisms do not actively accumulate the drug and that there may be a permeability barrier limiting its entry.

\section{Electron microscopy}

No marked alteration in mitochondrial morphology was evident in thin sections of organisms grown with chloramphenicol (P1. I, fig. I, 2). As in normal organisms the mitochondria were numerous and showed extremely well developed and extensively invaginated inner (cristae) membranes. Negative staining with phosphotungstate revealed that the inner membranes of mitochondria from organisms grown in the presence of chloramphenicol still possessed their characteristic $9 \mathrm{~nm}$. stalked subunits (P1. 2, fig. 3).

Table I. Cytochrome and flavoprotein content of mitochondria isolated from Polytomella caeca grown with and without chloramphenicol

Mean values presented together with standard deviations and number of different mitochondrial suspensions assayed.

$\begin{array}{ccc}\text { Electron transport component } & \overbrace{\begin{array}{c}\text { Without } \\ \text { chloramphenicol }\end{array}}^{\text {Content (m } \mu \text { moles/mg. protein) }} & \overbrace{\begin{array}{c}\text { With chloramphenicol } \\ \text { (I mg./ml.) }\end{array}}^{\text {m }} \\ \text { Cytochrome }\left(a+a_{3}\right) & 0.56 \pm 0.03(4) & 0.34 \pm 0.04(5) \\ \text { Cytochrome } b & 0.47 \pm 0.05(4) & 0.33 \pm 0.05(5) \\ \text { Cytochrome } c & 0.23 \pm 0.04(4) & 0.23 \pm 0.1(5) \\ \text { Flavoprotein } & 0.28 \pm 0.04(3) & 0.34 \pm 0.05(3)\end{array}$

Table 2. Oxidative activities of mitochondria isolated from Polytomella caeca grown with and without chloramphenicol

Figures presented are the mean values together with standard deviations and number of different mitochondrial suspensions assayed. Figures for succinoxidase and NADH oxidase refer to oxygen uptake rates; other figures are cytochrome redox rates.

\begin{tabular}{|c|c|c|}
\hline \multirow[b]{2}{*}{ Enzyme } & \multicolumn{2}{|c|}{$\begin{array}{c}\text { Specific activity } \\
\text { (m } \mu \text { moles/mg. protein/min.) }\end{array}$} \\
\hline & $\begin{array}{l}\text { Without } \\
\text { chloramphenicol }\end{array}$ & $\begin{array}{l}\text { With } \\
\text { chloramphenicol } \\
\text { (I mg. } / \mathrm{ml} \text { ) }\end{array}$ \\
\hline Succinoxidase & $44 \pm 4(5)$ & $25 \pm 2(5)$ \\
\hline NADH oxidase & $6 I \pm 2(4)$ & $I 8 \pm I(4)$ \\
\hline Succinate-cytochrome $c$ oxidoreductase $\left(V_{\max }\right)$ & $6 \mathrm{I} \pm 9(2)$ & $69 \pm 6(2)$ \\
\hline $\begin{array}{l}\text { NADH-cytochrome } c \text { oxidoreductase } \\
\text { (rotenone insensitive) }\left(V_{\max }\right)\end{array}$ & $5 \mathrm{I} \pm \mathrm{II}(3)$ & $5 I \pm 9(3)$ \\
\hline Cytochrome $c$ oxidase & $1266 \pm 350(6)$ & $581 \pm 166(7)$ \\
\hline
\end{tabular}

\section{Experiments with isolated mitochondria}

Cytochrome and flavoprotein content. The mitochondrial content of cytochromes and flavoproteins is shown in Table $\mathrm{I}$. There was a $40 \%$ decrease in the content of cytochromes $\left(a+a_{3}\right)$ in mitochondria isolated from organisms grown with chloramphenicol, while the effect on cytochrome $b$ was hardly significant and the cytochrome $c$ content not measurably affected. 
Electron-transport activities. Succinoxidase activity, a measure of the electrontransport capacity of the integrated respiratory chain, was decreased by $43 \%$ in mitochondria from organisms grown with chloramphenicol (Table 2). Succinatelinked reduction of added mammalian cytochrome $c$ was not significantly lower in such mitochondria, whereas the cytochrome $c$ oxidase activity was reduced.

The pathway of electrons from externally added NADH to oxygen in intact mitochondria from Polytomella caeca is not precisely established, but there is evidence that the initial steps occur outside the NAD-impermeable barrier (Lloyd \& Chance, 1968). A $72 \%$ decrease of NADH-oxidase activity was produced by growth in the presence of choramphenicol, although the rotenone-insensitive NADH-cytochrome $c$ reductase activity of intact mitochondria was unaffected.

Table 3. Steady-state levels of reduction of electron-transport components (substrate 6 mM-succinate), and half-times for their reduction in the aerobic-anaerobic transition (state $4 \rightarrow$ state 5) in mitochondria from Polytomella caeca grown in the absence and presence of chloramphenicol

$100 \%$ reduction of a component taken as anaerobic reduction level minus level in absence of exogenous substrate (state 5-state 2) (Chance \& Williams, 1956). Absence of a figure indicates that if any reduction occurred it was below the limit of detection. Figures representative of results obtained with eight different mitochondrial suspensions. Temperature of incubation $20^{\circ}$.

Electron-transport component

Wavelength pair (nm.)

$t \frac{1}{2}$ red $^{n}$ state $4 \rightarrow$ state 5 (sec.)

$\%$ red $^{n}$ state 4

$\%$ not reduced in state 5 but reduced by dithionite

$t \frac{1}{2} \mathrm{red}^{n}$ state $4 \rightarrow$ state 5 (sec.)

$\%$ red $^{n}$ state 4

$\%$ not reduced in state 5 but reduced by dithionite

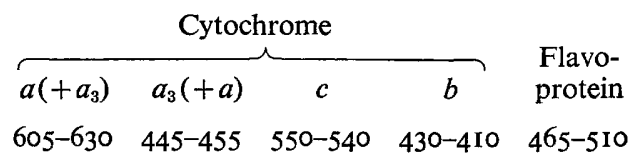

Without chloramphenicol

\begin{tabular}{|c|c|c|c|c|}
\hline $\begin{array}{c}2 \cdot 0 \\
5.0\end{array}$ & $\begin{array}{r}2 \cdot 5 \\
-\end{array}$ & $\begin{array}{r}I \cdot 0 \\
2 I \cdot 0\end{array}$ & $\begin{array}{r}I \cdot 3 \\
48 \cdot 0\end{array}$ & $\begin{array}{r}I \cdot 3 \\
26 \cdot 0\end{array}$ \\
\hline- & - & - & $33^{\circ} 0$ & $39^{\circ} 0$ \\
\hline \multicolumn{5}{|c|}{ With choramphenicol } \\
\hline$\frac{7 \cdot 5}{-}$ & $\begin{array}{l}7 \cdot 5 \\
6 \cdot 4\end{array}$ & $\begin{array}{r}5.0 \\
14.0\end{array}$ & $\begin{array}{r}7 \cdot 0 \\
44.3\end{array}$ & $\begin{array}{r}7 \cdot 0 \\
23 \cdot 2\end{array}$ \\
\hline- & - & - & $37^{\circ} 0$ & $49 \cdot 0$ \\
\hline
\end{tabular}

An investigation of the steady-state levels of reduction of the various electrontransport components during succinate respiration indicated that there are no marked differences in the cytochrome or flavoprotein redox levels between mitochondria from organisms grown normally and with chloramphenicol (Table 3). However, all the electron-transport components studied in mitochondria from organisms grown with chloramphenicol showed a three- to five-fold slower response during the aerobic (state 4) to anaerobic (state 5) transition. In the anaerobic state cytochromes $\left(a+a_{3}\right)$ and $c$ were fully reduced, and the addition of excess dithionite produced no further responses. Further reduction of cytochrome $b$ and flavoprotein was, however, produced on dithionite addition to anaerobic mitochondrial suspensions; the dithionite-reducible flavoprotein accounted for a greater proportion of the total flavoprotein in mitochondria which had been isolated from organisms grown with chloramphenicol. 


\section{DISCUSSION}

Growth of Polytomella caeca in the presence of chloramphenicol, as is the case with various species of both facultatively anerobic and obligately aerobic yeasts (ClarkWalker \& Linnane, 1967) and also Pythium ultimatum (Marchant \& Smith, 1968), leads to respiratory deficiency. Whereas in yeast this deficiency is correlated with disorganized mitochondria and a partial loss of all membrane-bound cytochromes $\left(a, a_{3}, b, c_{1}\right)$, these organelles in chloramphenicol-grown Polytomella caeca are not structurally impaired as seen at the resolution possible in the electron microscope, and are deficient only in cytochrome oxidase. However, the turnover number of cytochrome oxidase is considerably greater than the turnover number required to account for the over-all electron-transport rate or oxygen consumption of isolated mitochondria (Chance, 1967; Lloyd \& Chance, 1968); the over-all decreased electrontransport capacity of Polytomella caeca mitochondrial suspensions appears to result from an impairment at the substrate end of the respiratory chain, rather than at the level of cytochrome oxidase. Thus, when oxygen is exhausted by respiration and the suspensions become anaerobic, the rates of reduction of all the electron-transport components studied are decreased. This, and the fact that the steady-state redox levels during succinate respiration are hardly altered, suggests that flavoproteincytochrome and cytochrome-cytochrome interactions are not interrupted in mitochondria from cells grown with the drug. Rather, it is a decreased supply of electrons at the dehydrogenase level which accounts for the lowered respiration rate of isolated mitochondria. Further evidence for the dislocation of flavoprotein (but not of cytochromes with the possible exception of cytochrome $b$ ) during growth with chloramphenicol is provided by the finding that the proportion of non-enzymically active flavoprotein (reducible only on dithionite addition) is increased. Tetrazolium salts accept electrons at the flavoprotein-cytochrome $b$ region of the respiratory chain (Lester \& Smith, 196I); thus the decreased capacity for dye reduction in intact organisms after growth with chloramphenicol reinforces the view that the lesion of electron transport occurs at the dehydrogenase level.

The characteristic $9 \mathrm{~nm}$. inner mitochondrial membrane subunits have been identified as $F_{1}$-ATPase, the terminal enzyme of oxidative phosphorylation in mammalian mitochondria; the oligomycin-sensitivity of this enzyme is dependent on the binding of the $F_{1}$ particles to the inner membrane (Kagawa \& Racker, 1966). Schatz (I968) observed a decreased oligomycin sensitivity of $F_{1}$-ATPase in chloramphenicol-grown yeast, and Marchant \& Smith (1968) were unable to detect the stalked subunits in the otherwise ultrastructurally normal mitochondria of chloramphenicol-grown Pythium ultimatum. Membrane binding of $F_{1}$-ATPase in Polytomella caeca mitochondria cannot be assessed by its oligomycin-sensitivity (no inhibition up to $200 \mu \mathrm{g} . / \mathrm{mg}$. protein, D. Lloyd, unpublished) but negative staining clearly revealed the presence of stalked $9 \mathrm{~nm}$. inner membrane subunits. It is of interest that these particles are not detached after growth with chloramphenicol in Polytomella caeca; changes in cytochrome redox states on ADP addition (D. Lloyd, unpublished results) confirm that these mitochondria are still capable of carrying out oxidative phosphorylation. 
The authors wish to thank Professor D. E. Hughes for his helpful criticism and Dr K. Vickerman, Mr W. J. Henderson and Mr G. I. Roach for skilled assistance with electron-microscope techniques. This work was done during the tenure of a Medical Research Council Studentship by D.A.E.

\section{REFERENCES}

BRAY, G. D. (I960). A simple efficient liquid scintillator for counting aqueous solutions in a liquid scintillation counter. Analytical Biochemistry x, 279.

ChANCE, B. (195I). Rapid and sensitive spectrophotometry. III. A double beam apparatus. Review of Scientific Instruments 22, 634.

CHANCE, B. (1967). The reactivity of haemoproteins. Biochemical Journal 1o3, I.

Chance, B. \& Williams, G. R. (I956). The respiratory chain and oxidative phosphorylation. Advances in Enzymology I7, 65.

Clark-Walker, G. \& LinNane, A. W. (1967). The biogenesis of mitochondria in Saccharomyces cerevisiae. A comparison between cytoplasmic respiratory deficient mutant yeast and chloramphenicol inhibited wild type cells. Journal of Cell Biology 34, I.

Haldar, D., Freeman, K. \& Work, T. S. (1966). Biogenesis of mitochondria. Nature 2II, 9.

Huang, M., Biggs, D. R., Clark-Walker, G. D. \& Linnane, A. W. (I966). Chloramphenicol inhibition of the formation of particulate mitochondrial enzymes of Saccharomyces cerevisiae. Biochimica et Biophysica Acta 144, 434.

KAGAWA, Y. \& RACKER, E. (1966). Correlation of morphology and function in submitochondrial particles. Journal of Biological Chemistry 24I, 2475.

Kroon, A. M. (1963). Protein synthesis in heart mitochondria. Biochimica et Biophysica Acta 72, 391.

Lamb, A. J., Clark-Walker, G. D. \& Linnane, A. W. (I968). The biogenesis of mitochondria. The in vitro differentiation of mitochondrial and cytoplasmic protein synthesizing systems by antibiotics. Biochimica et Biophysica Acta r6r, 415.

LESTER, R. L. \& SMITH, A. L. (I96I). Mode of reduction of tetrazolium salts by beef heart mitochondria; role of coenzyme Q and other lipids. Biochimica et Biophysica Acta 47, 475 .

LLoYd, D. (1966). The isolation of mitochondria from the colourless alga, Prototheca zopfii. Experimental Cell Research 45, 120.

Lloyd, D. \& Brookman, J. S. G. (1967). An oxygen electrode reaction vessel. Biotechnology and Bioengineering 9, $27 \mathrm{I}$.

LLoyd, D. \& ChANCE, B. (1968). Electron transport in mitochondria isolated from the flagellate, Polytomella caeca. Biochemical Journal ro7, 829.

Lloyd, D., Evans, D. A. \& Venables, S. E. (I968). Propionate assimilation in the flagellate, Polytomella caeca: an inducible mitochondrial enzyme system. Biochemical Journal 109, 897.

Lowry, O. H., Rosebrough, N. J., FARR, A. L. \& Randall, R. J. (I95I). Protein measurement with the Folin phenol reagent. Journal of Biological Chemistry 193, 265.

MAGER, I. (1960). Chloramphenicol and chlortetracycline inhibition of amino acid incorporation into proteins in a cell-free system from Tetrahymena pyriformis. Biochimica et Biophysica Acta 38,150 .

Marchant, R. \& Smith, D. G. (1968). The effect of chloramphenicol on growth and mitochondrial structure of Pythium ultimatum. Journal of General Microbiology 50, 39I.

PARsons, D. F. (1963). Mitochondrial structure: two types of subunits on negatively stained mitochondrial membranes. Science $\mathbf{1 4 0}, 985$.

RoodyN, D. B. (1962). Controlled disruption and subfractionation of mitochondria labelled in vitro with radioactive valine. Biochemical Journal 85, 177.

SCHATZ, G. (1968). Impaired binding of mitochondrial ATPase in cytoplasmic 'petite' mutant of Saccharomyces cerevisiae. Journal of Biological Chemistry 243, 2192.

SмITH, L. (1955). Cytochrome oxidase. Methods in Enzymology 2, 736.

TURNER, G. \& LLOYD, D. (1970). The effect of growth with chloramphenicol on the mitochondria of Tetrahymena pyrifomis. Biochemical Journal II6, 4Ip..

Umbreit, W. W., Burris, R. H. \& StAUffer, J. F. (1957). In Manometric Techniques, p. I. Minneapolis: Burgess Publishing Co. 

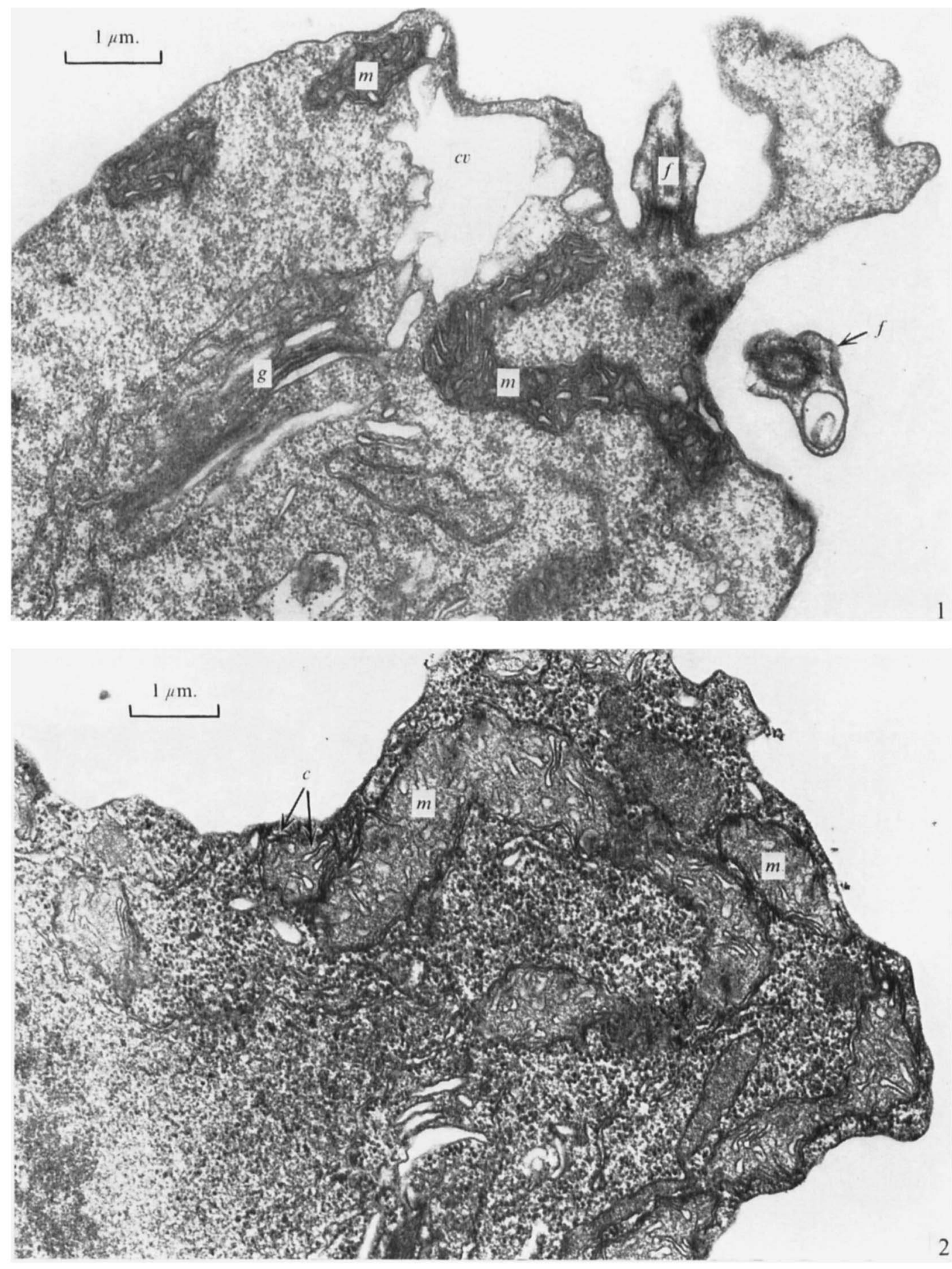

D. LLOYD, D. A. EVANS AND S. E. VENABLES

(Facing p. 40) 


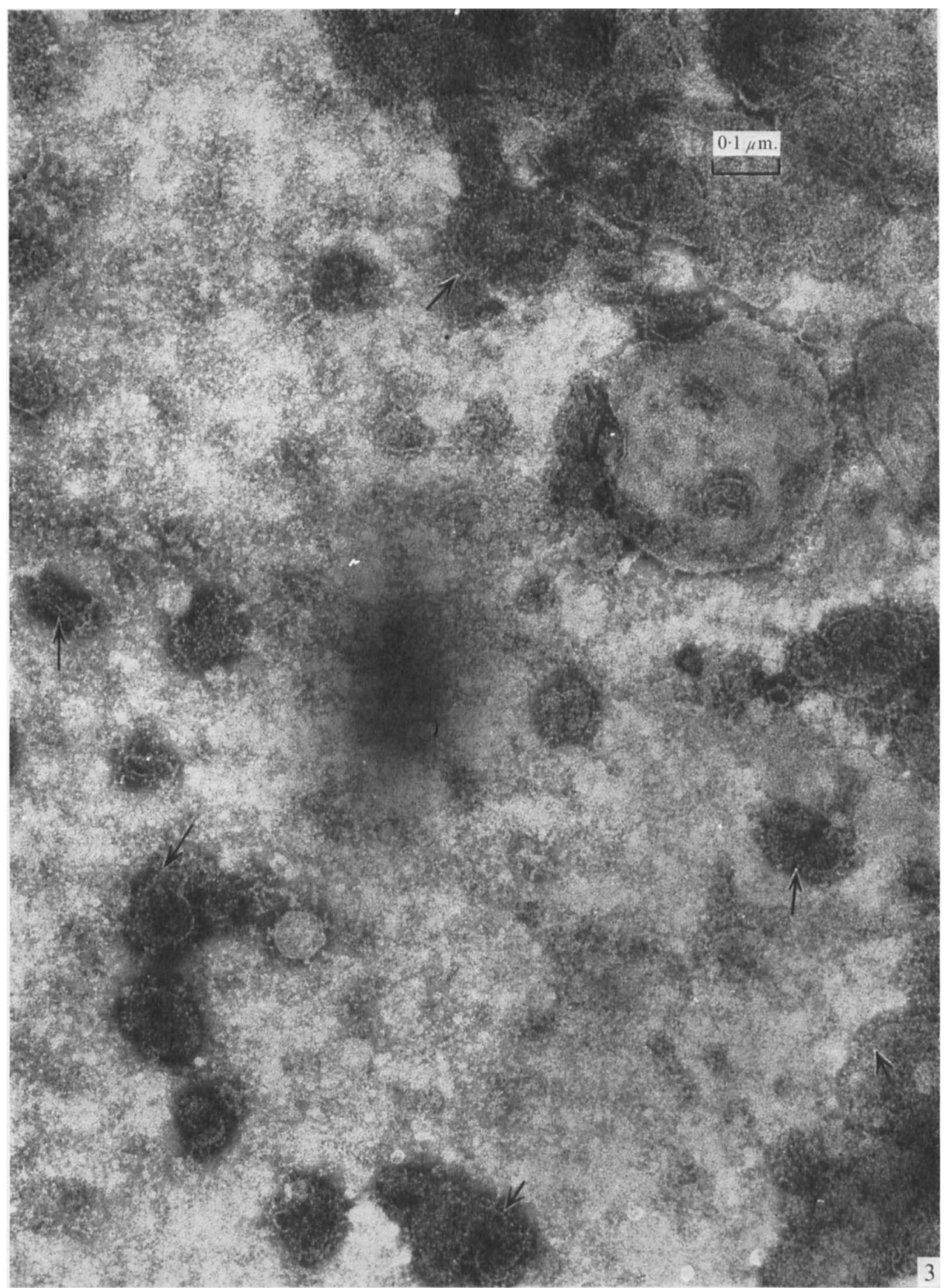

D. LLOYD, D. A. EVANS AND S. E. VENABLES 
Wilkie, D., Saunders, G. \& LinNane, A. W. (1967). Inhibition of respiratory enzyme synthesis in yeast by chloramphenicol: relationship between chloramphenicol tolerance and resistance to other antibacterial antibiotics. Genetical Research ro, 199.

WoodwARD, D. O. \& MUNKRES, K. D. (1966). Alterations of a maternally inherited mitochondrial structural protein in respiratory-deficient strains of Neurospora. Proceedings of the National Academy of Sciences of the United States of America 55, 872.

\section{EXPLANATION OF PLATES}

\section{Plate I}

Fig. I. Polytomella caeca: section of organism grown without chloramphenicol showing contractile vacuole $(c v)$, two flagella $(f)$, Golgi region $(g)$ and mitochondria $(m) . \times 18,000$.

Fig. 2. Section of organism grown in the presence of chloramphenicol I mg./mI., showing mitochondria $(m)$ with numerous cristae $(c) . \times 18,000$.

\section{Plate 2}

Fig. 3. Mitochondria isolated from Polytomella caeca grown with chloramphenicol $\mathrm{I} \mathrm{mg} . / \mathrm{ml}$. and negatively stained with $\mathrm{K}$ phosphotungstate. Arrows indicate rows of stalked particles with $9 \mathrm{~nm}$. heads which cover the inner surface of the inner mitochondrial membrane. $\times 120,000$. 